\title{
Relações metionina mais cistina digestível:lisina digestível em dietas suplementadas com ractopamina para suínos em terminação ${ }^{1}$
}

\section{Sérgio de Miranda Pena ${ }^{2}$, Darci Clementino Lopes ${ }^{3}$, Horacio Santiago Rostagno ${ }^{3}$, Francisco Carlos de Oliveira Silva ${ }^{4}$, Juarez Lopes Donzele ${ }^{3}$}

\author{
${ }^{1}$ Elanco Saúde Animal. \\ 2 Programa de Pós-graduação em Zootecnia - Universidade Federal de Viçosa - UFV. Bolsista do CNPq. \\ ${ }^{3}$ Departamento de Zootecnia - Universidade Federal de Viçosa - UFV. \\ ${ }^{4}$ EPAMIG.
}

RESUMO - O experimento foi realizado com o objetivo de determinar a relação metionina+cistina digestível:lisina digestível (met+cis:lis) para suínos machos castrados, selecionados geneticamente para deposição de carne magra na carcaça, sob suplementação com ractopamina (RAC) na fase de terminação. Foram utilizados 64 suínos com peso inicial de $84,68 \pm$ $1,34 \mathrm{~kg}$, distribuídos em delineamento experimental de blocos ao acaso. Os tratamentos consistiram de quatro dietas com relações de 0,$54 ; 0,58 ; 0,62$ e 0,66 de met+cis:lis suplementadas com RAC, oito repetições e dois animais por unidade experimental, durante um período de 28 dias. As relações met+cis:lis não influenciaram o consumo de ração, o ganho de peso diário, a conversão alimentar, a espessura de toucinho, a quantidade de carne magra, o peso da carcaça, a porcentagem de carne magra e o rendimento de carcaça dos suínos. As relações met+cis:lis influenciaram de forma quadrática as concentrações de colesterol total no lombo e de forma linear as concentrações de colesterol no toucinho. O menor teor de colesterol total foi observado nos suínos alimentados com a dieta com relação 0,66 met+cis:lis. Em suínos de 85 a 109 kg sob suplementação com ractopamina, a relação 0,54 met+cis:lis atende às exigências para melhor desempenho e melhores características de carcaça, enquanto, para menores níveis de colesterol no lombo e no toucinho, a relação é de 0,66 met+cis:lis.

Palavras-chave: aminoácidos sulfurosos, características de carcaça, colesterol, desempenho

\section{Digestible methionine plus cystine to digestible lysine ratio in diets supplemented with ractopamine for finishing pigs}

\begin{abstract}
The experiment was carried out to determine digestible methionine + cystine: digestible lysine (Met + Cys/Lys) ratio for barrows selected for deposition of lean meat in the carcass supplemented with ractopamine (RAC) in the finishing phase. Sixty-four barrows with $84.68 \pm 1.34 \mathrm{~kg} \mathrm{BW}$ was allotted to an experimental randomized block design, fed diets containing four Met + Cys/Lys ratio $(0.54,0.58,0.62$ and 0.66) supplemented with ractopamine, eight replications, during a period of 28 days. Met + Cys/Lys did not affect feed intake, average daily gain, feed conversion, fat thickness, lean meat amount, carcass weight, lean meat percentage and carcass yield of pigs. Met + Cys/Lys ratio influence quadraticaly the concentrations of total cholesterol in the loin and linearly the cholesterol concentrations in the subcutaneous fat. The lowest levels of total cholesterol were observed in pigs fed diet with $0.66 \mathrm{Met}+\mathrm{Cys} / \mathrm{Lys}$ ratio. In pigs from 85 to $109 \mathrm{~kg}$ supplemented with ractopamine, the $0.54 \mathrm{Met}+\mathrm{Cys} / \mathrm{Lys}$ ratio meets the requirement for better performance and better carcass traits, while to lower the cholesterol levels in the loin and subcutaneous fat the requirement is $0.66 \mathrm{Met}+\mathrm{Cys} / \mathrm{Lys}$ ratio.
\end{abstract}

Key Words: carcass characteristic, cholesterol, performance, sulfur amino acids

\section{Introdução}

A crescente demanda do consumidor por carne suína mais magra tem aumentado o interesse de produtores e frigoríficos pelo abate de suínos com maior quantidade de carne magra e baixo teor de gordura corporal.

O incremento calórico decorrente da deposição de gordura é menor que o da deposição de proteína, entre- tanto, com a deposição de proteína, ocorre também grande deposição de água, o que não ocorre com a deposição de gordura, que absorve baixa quantidade de água. Logo, em ganho de peso, a deposição de proteína é mais interessante que a de gordura.

Um dos aditivos disponíveis no mercado para aumentar a deposição de proteína é a ractopamina, um $\beta$-agonista adrenérgico que tem aumentado a deposição muscular e 
reduzido a de gordura corporal, melhorando o desempenho dos animais (Marchant-Forde et al., 2003; Armstrong et al., 2004).

Animais sob suplementação com ractopamina apresentam maior exigência de lisina, aminoácido direcionado quase totalmente para deposição muscular (Schinckel et al., 2000; Apple et al., 2004). No entanto, como a lisina tem sido o aminoácido-referência no conceito de proteína ideal, a relação dos outros aminoácidos essenciais com a lisina pode ser alterada em dietas suplementadas com ractopamina.

As exigências de aminoácidos sulfurosos são controladas pela exigência de mantença, e não pela exigência para deposição de proteína, portanto, não aumentam proporcionalmente às exigências de lisina quando há aumento na deposição de proteína. Segundo Mavromichalis \& Cera (2001), suínos com maior ganho em carne e melhor desempenho têm maior exigência de lisina e menor relação dos aminoácidos sulfurosos com a lisina.

Assim, objetivou-se com este trabalho determinar a relação metionina + cistina digestível:lisina digestível (met+cis:lis) para suínos machos castrados selecionados geneticamente para deposição de carne magra na carcaça sob suplementação com ractopamina na fase de terminação.

\section{Material e Métodos}

O experimento foi conduzido na Granja de Suínos da Fazenda Experimental Vale do Piranga, pertencente à Empresa de Pesquisa Agropecuária de Minas Gerais (EPAMIG), localizada no município de Oratórios, Minas Gerais, no período de janeiro a fevereiro de 2006.

Os animais foram alojados em baias com área disponível de $1,93 \mathrm{~m}^{2}$ por animal, providas de comedouro semi-automático e bebedouro tipo chupeta, em galpão de alvenaria com piso de concreto e coberto com telhas de amianto. Utilizaram-se 64 suínos machos castrados de alto potencial genético para deposição de carne magra na carcaça, com peso inicial de 84,68 $\pm 1,34 \mathrm{~kg}$, distribuídos em delineamento de blocos ao acaso, composto de quatro tratamentos e oito repetições de dois animais, durante um período de 28 dias. O peso dos suínos foi adotado como critério na formação dos blocos.

As temperaturas do ar foram monitoradas diariamente por meio de termômetros de máxima e mínima, localizados dentro do galpão, à meia-altura do corpo dos animais, externamente às baias.

Como tratamentos, avaliaram-se rações suplementadas com 5 ppm de ractopamina e contendo $0,936 \%$ de lisina digestível (lis), resultando em 0,54; 0,58; 0,62 e 0,66 de metionina + cistina digestível (met + cis) em relação à lisina digestível, correspondendo aos seguintes níveis 0,505 ; 0,$543 ; 0,580 ; 0,617 \%$ de metionina + cistina digestível.

Antes do período experimental, os animais passaram por um período de sete dias de adaptação às baias, em que receberam uma ração prática composta principalmente de milho e farelo de soja para a fase de terminação contendo clortetraciclina (contém por quilograma do produto: $200 \mathrm{~g}$ de clortetraciclina) $(2,25 \mathrm{~kg} / \mathrm{t})$ e tilosina $\left(\right.$ Tylan ${ }^{\circledR} 40$ Premix, contém por quilograma do produto: atividade de tilosina [como fosfato], $88 \mathrm{~g}$; e veículo q.s.p., $1.000 \mathrm{~g}$ ).

As rações experimentais (Tabela 1) foram formuladas utilizando-se, entre outros ingredientes, milho, sorgo e farelo de soja para atender às exigências nutricionais dos animais, exceto de metionina + cistina digestível. $\mathrm{Na}$ avaliação das relações aminoacídicas das rações, foram utilizadas as relações preconizadas por Rostagno et al. (2005) para suínos em fase de terminação.

Água e ração foram fornecidas à vontade durante todo o período experimental. As sobras foram coletadas diariamente e somadas às sobras do comedouro no final do período experimental.

As rações foram pesadas durante todo o período experimental e os animais foram pesados individualmente, no início e no final do período experimental (28 dias), permitindo dessa forma determinar o ganho de peso diário (GPD), a conversão alimentar (CA), o consumo diário de ração diário (CDR) e o consumo diário de metionina mais cistina digestível (CMC).

Além desses parâmetros, foram avaliados a espessura de toucinho (ET), o rendimento de carne magra (RCM), a quantidade de carne magra (QCM), a porcentagem de carne magra na carcaça (PCM) e o índice de bonificação (IB), por meio de aparelho de tipificação de carcaça com pistola Henessy, conforme procedimentos adotados no frigorífico. Avaliaram-se ainda o teor de colesterol total (CT), o peso da carcaça (PC) quente, o peso final (PF) no momento da retirada da ração, o peso ao abate (PA) após 18 horas de jejum e o rendimento de carcaça ( $\mathrm{RC})$, calculado como a relação percentual entre o peso de carcaça e o peso ao abate.

Ao final do período experimental, quando atingiram 28 dias de consumo das dietas experimentais e peso final de $109,8 \pm 4,49 \mathrm{~kg}$, os animais foram mantidos em jejum por 18 horas e encaminhados para o abate, realizado a $5 \mathrm{~km}$ do galpão experimental. Após o abate, as carcaças foram mantidas em câmara fria $\left(2 \mathrm{a} 4^{\circ} \mathrm{C}\right)$ por 18 horas.

A meia-carcaça direita foi escolhida (NPPC, 1991) para a coleta dos cortes de lombo (Longissimus dorsi) e de toucinho para posteriores análises de colesterol total. As 
Tabela 1 - Composições centesimal e calculada das rações experimentais

\begin{tabular}{|c|c|c|c|c|}
\hline \multirow[t]{3}{*}{ Ingrediente $(\%)$} & \multicolumn{4}{|c|}{ Com ractopamina } \\
\hline & \multicolumn{4}{|c|}{$\begin{array}{c}\text { Relação metionina }+ \text { cistina } \\
\text { dig:lisina digestível }\end{array}$} \\
\hline & 0,54 & 0,58 & 0,62 & 0,66 \\
\hline Milho & 37,854 & 37,845 & 37,808 & 37,771 \\
\hline Sorgo baixo tanino & 40,000 & 40,000 & 40,000 & 40,000 \\
\hline Farelo de soja $45 \%$ & 19,152 & 19,152 & 19,152 & 19,152 \\
\hline Óleo de soja & 0,148 & 0,148 & 0,148 & 0,148 \\
\hline Fosfato bicálcico & 0,807 & 0,807 & 0,807 & 0,807 \\
\hline Calcário & 0,575 & 0,575 & 0,575 & 0,575 \\
\hline Sal & 0,346 & 0,346 & 0,346 & 0,346 \\
\hline Amido & 0,029 & - & - & - \\
\hline L-lisina $\mathrm{HCl}$ & 0,399 & 0,399 & 0,399 & 0,399 \\
\hline DL-metionina & 0,054 & 0,092 & 0,129 & 0,166 \\
\hline L-treonina & 0,142 & 0,142 & 0,142 & 0,142 \\
\hline L-triptofano & 0,019 & 0,019 & 0,019 & 0,019 \\
\hline Paylean ${ }^{\circledR} 20^{1}$ & 0,025 & 0,025 & 0,025 & 0,025 \\
\hline $\begin{array}{l}\text { Premix vitaminas } \\
\text { minerais+aditivos }^{2}\end{array}$ & 0,400 & 0,400 & 0,400 & 0,400 \\
\hline Tylan $^{\circledR} 40$ Premix $^{3}$ & 0,050 & 0,050 & 0,050 & 0,050 \\
\hline \multicolumn{5}{|l|}{ Composição calculada ${ }^{4}$} \\
\hline $\begin{array}{l}\text { Energia metabolizável } \\
(\mathrm{kcal} / \mathrm{kg})\end{array}$ & 3.230 & 3.230 & 3.230 & 3.230 \\
\hline Proteína bruta (\%) & 15,500 & 15,500 & 15,500 & 15,500 \\
\hline Lisina total $(\%)$ & 1,017 & 1,017 & 1,017 & 1,017 \\
\hline Lisina digestível (\%) & 0,936 & 0,936 & 0,936 & 0,936 \\
\hline $\begin{array}{l}\text { Metionina + cistina } \\
\text { digestível }(\%)\end{array}$ & 0,505 & 0,543 & 0,580 & 0,617 \\
\hline Treonina digestível (\%) & 0,627 & 0,627 & 0,627 & 0,627 \\
\hline Triptofano digestível (\%) & 0,178 & 0,178 & 0,178 & 0,178 \\
\hline Valina digestível (\%) & 0,660 & 0,660 & 0,660 & 0,660 \\
\hline Cálcio (\%) & 0,490 & 0,490 & 0,490 & 0,490 \\
\hline Fósforo total (\%) & 0,445 & 0,445 & 0,445 & 0,445 \\
\hline Fósforo disponível (\%) & 0,250 & 0,250 & 0,250 & 0,250 \\
\hline Sódio $(\%)$ & 0,160 & 0,160 & 0,160 & 0,160 \\
\hline
\end{tabular}

${ }_{1}$ Paylean ${ }^{\circledR} 20$ - Conteúdo/kg: Cloridrato de ractopamina - 20 g; veículo q.s.p.

2 Terminação - conteúdo/kg: vit. A - 750.000,00 UI; vit. D3 - 125.000,00 UI: vit. E - 3.000,00 mg; vit. K3 - 125,00 mg; vit. B1 - 100,00 mg; vit. B2 $660,00 \mathrm{mg}$; vit. B6 - $125,00 \mathrm{mg}$; vit. B12 - 3.000,00 mcg; niacina - $3.750,00 \mathrm{mg}$; pantotenato de cálcio - $1.875,00 \mathrm{mg}$; ácido fólico - 200,00 mg; colina $10.500,00 \mathrm{mg} ; \mathrm{Fe}-8.750,00 \mathrm{mg}$; $\mathrm{Cu}-3.750,00 \mathrm{mg} ; \mathrm{Mn}-6.250,00 \mathrm{mg}$; $\mathrm{Zn}-18.750,00 \mathrm{mg}$; I - 250,00 mg; Se - 75,00 mg; antioxidante - $500,00 \mathrm{mg}$; veículo.

${ }^{3} \operatorname{Tylan}^{\circledR} 40$ Premix - conteúdo/kg: fosfato de tilosina - $88 \mathrm{~g}$; veículo - q.s.p. $1.000 \mathrm{~g}$.

${ }^{4}$ Composição calculada segundo Rostagno et al. (2005).

amostras foram obtidas entre a $10^{\mathrm{a}}$ e a $11^{\mathrm{a}}$ vértebra lombar. As amostras coletadas foram embaladas a vácuo em equipamento utilizado no frigorífico, dentro de embalagens plásticas de polietileno com náilon. As amostras embaladas foram transportadas em caixas de isopor com gelo para um congelador e depois levadas para o Departamento de Ciência de Alimentos da Faculdade de Engenharia de Alimentos da Universidade Estadual de Campinas-FEA(UNICAMP), para análise de colesterol total por Cromatografia Líquida de Alta Eficiência (CLAE), conforme descrito por Nogueira \& Bragagnolo (2002) e Saldanha et al. (2004).
As variáveis foram analisadas utilizando-se o Sistema de Análises Estatísticas e Genéticas (SAEG), desenvolvido na Universidade Federal de Viçosa (2004), versão 9.0, utilizando-se os procedimentos para análise de variância e regressão, segundo o modelo:

$$
\mathrm{Y}_{\mathrm{ij}}=\mathrm{m}+\mathrm{t}_{\mathrm{i}}+\mathrm{b}_{\mathrm{j}}+\mathrm{e}_{\mathrm{ij}}
$$

em que $\mathrm{i}=1,2,3 \ldots, \mathrm{I} ; \mathrm{j}=1,2,3 \ldots, \mathrm{j} ; \mathrm{Y}_{\mathrm{ij}}=$ valor observado na parcela relativa ao tratamento i no bloco $\mathrm{j} ; \mathrm{m}=$ média geral; $\mathrm{t}_{\mathrm{i}}=$ efeito do tratamento $; \mathrm{b}_{\mathrm{j}}=$ efeito do bloco $; \mathrm{e}_{\mathrm{ij}}=$ efeito dos fatores não controlados (erro experimental).

As estimativas da relação metionina + cistina digestível:lisina digestível na presença de ractopamina foram determinadas por meio de análises de regressão linear e quadrática e/ou pelo modelo descontínuo Linear Response Plateau (LRP), conforme o melhor ajustamento obtido para cada variável, considerando o comportamento biológico dos animais.

\section{Resultados e Discussão}

As temperaturas máximas e mínimas com seus respectivos desvios-padrão foram $33,02 \pm 1,77^{\circ} \mathrm{Ce} 21,36 \pm 1,38^{\circ} \mathrm{C}$, respectivamente. Essas altas temperaturas determinaram piora no desempenho de suínos, principalmente pela redução no consumo de alimentos e pelo custo energético, associado aos processos de termorregulação. Manno et al. (2006) avaliaram os efeitos da temperatura ambiente sobre o desempenho de suínos dos 30 aos 60 kg e concluíram que a alta temperatura influenciou negativamente o ganho de peso dos animais. Do mesmo modo, Tavares et al. (2000) constataram que animais expostos ao calor apresentaram menor ganho de peso, menor consumo de ração e pior eficiência de utilização do alimento.

Neste estudo, apesar de os animais serem de alto potencial genético para deposição de carne magra, o desempenho foi inferior à média para esta fase, o que pode ser explicado pelas elevadas temperaturas registradas no experimento, que ocasionaram redução do consumo de ração e do ganho de peso diário. As relações met+cis:lis não afetaram $(\mathrm{P}>0,10)$ os pesos final e ao abate, o ganho de peso, o consumo de ração e a conversão alimentar dos animais sob suplementação com ractopamina (Tabela 2).

Os resultados de ganho de peso foram semelhantes aos encontrados por Knowles et al. (1998), que, em dois experimentos com suínos em fase de terminação, não encontraram efeito das relações met+cis:lis sobre o ganho de peso diário. Foram semelhantes também aos resultados descritos por Dean (2005) de que o aumento da concentração de metionina + cistina na ração não afeta o ganho de 
peso diário em relação superior a 0,48 met+cis:lis para suínos em terminação.

Loughmiller et al. (1996b), no entanto, observaram que o ganho de peso diário de suínos em terminação tendeu a diminuir com o aumento na concentração de metionina + cistina digestível na dieta. Os resultados de consumo de ração obtidos nesta pesquisa foram similares àqueles descritos por Loughmiller et al. (1996a) e Dean (2005). Santos et al. (2007) também verificaram que o consumo de ração dos suínos em terminação não foi influenciado pelos níveis de metionina + cistina da ração.

Os resultados de conversão alimentar observados neste estudo confirmam aqueles verificados por Loughmiller et al. (1996a) e Dean (2005), que não constataram variação significativa na conversão alimentar dos suínos em terminação, em razão do aumento da concentração de metionina + cistina na ração. De forma contrária, Santos et al. (2007) verificaram melhora na conversão alimentar de suínos em terminação à medida que a concentração de metionina + cistina aumentou até o nível estimado de $0,506 \%$, correspondente à relação met+cis:lis de 0,63 .

As relações met+cis:lis influenciaram $(\mathrm{P}<0,01)$ o consumo de metionina + cistina, que aumentou de forma linear segundo a equação: $\hat{\mathrm{Y}}=-0,025+21,75 \mathrm{X}\left(\mathrm{r}^{2}=0,99\right)$. Resultados semelhantes foram obtidos por Kiefer et al. (2005) em ambiente de alta temperatura, no qual o consumo diário de metionina + cistina digestível dos suínos em crescimento aumentou de forma linear com o aumento do nível dietético de aminoácidos sulfurados.

Aumento linear no consumo de metionina + cistina decorrente da elevação dos níveis de aminoácidos sulfurados na ração também foi observado por Santos et al. (2007). Nesta pesquisa, a ausência de variação significativa no consumo de ração pode explicar o aumento no consumo de metionina + cistina.
Não houve efeito $(\mathrm{P}>0,10)$ das relações met+cis:lis sobre a espessura de toucinho na carcaça (Tabela 3 ). Resultados similares foram obtidos por Loughmiller et al. (1996a,1996b, 1998), Santos et al. (2007) e Kowles et al. (1998), que também não observaram efeito dos níveis de met+cis da ração sobre a espessura de toucinho dos suínos na fase de terminação.

A quantidade de carne magra dos animais não foi influenciada $(\mathrm{P}>0,10)$ pelas relações metionina + cistina:lisina das rações. Knowles et al. (1998) observaram incremento na quantidade de carne magra na carcaça com o aumento da relação met+cis:lis até 0,55 , no qual a quantidade de carne magra na carcaça passou a diminuir. Esses resultados contrariam, no entanto, os descritos por Santos et al. (2007), que verificaram aumento da quantidade de carne magra na carcaça de suínos com o aumento da relação met+cis: lis até 0,63 .

$\mathrm{O}$ peso da carcaça (PC) dos suínos não foi influenciado $(\mathrm{P}>0,10)$ pelas relações met+cis:lis. Resultados similares foram obtidos por Loughmiller et al. (1996a) e Santos et al. (2007), que também não observaram efeito do aumento da relação met+cis:lis na ração sobre o peso de carcaça. Em outro trabalho, Knowles et al. (1998) relataram efeito cúbico do peso de carcaça em resposta ao aumento da relação met+cis:lis.

A porcentagem de carne magra (PCM) não foi influenciada $(\mathrm{P}>0,10)$ pelas relações met+cis:lis. Estes resultados corroboram os relatos de Loughmiller et al. (1996b), Knowles et al. (1998) e Santos et al. (2007), que também não observaram efeito da elevação da relação de met+cis:lis na dieta sobre a porcentagem de carne magra dos animais.

A resposta em porcentagem de carne magra obtida neste estudo foi similar àquela relatada por Knowles et al. (1998), em que a relação ótima de met+cis:lis para melhor desempenho e características de carcaça de suínos em terminação não é maior que 0,47 e com o de Lougmiller et al.

Tabela 2 - Desempenho de suínos machos castrados em terminação alimentados com rações suplementadas com ractopamina e diversas relações metionina + cistina:lisina

\begin{tabular}{|c|c|c|c|c|c|c|}
\hline \multirow[t]{2}{*}{ Variável } & \multicolumn{4}{|c|}{$\begin{array}{c}\text { Relação metionina + cistina digestível: } \\
\text { lisina digestível com ractopamina }\end{array}$} & \multirow[t]{2}{*}{$\mathrm{CV}(\%)$} & \multirow[t]{2}{*}{ EPM } \\
\hline & 0,54 & 0,58 & 0,62 & 0,66 & & \\
\hline Peso inicial (kg) & 84,67 & 84,55 & 84,64 & 84,67 & - & 0,17 \\
\hline Peso final $(\mathrm{kg})$ & 109,97 & 109,64 & 109,68 & 110,30 & 1,80 & 0,58 \\
\hline Peso ao abate (kg) & 106,71 & 106,45 & 106,91 & 106,21 & 1,67 & 0,51 \\
\hline Ganho de peso (g/dia) & 903 & 896 & 894 & 915 & 5,80 & 20,78 \\
\hline Consumo de ração (g/dia) & 2.343 & 2.303 & 2.315 & 2.334 & 6,88 & 34,20 \\
\hline Conversão alimentar (g/g) & 2,59 & 2,57 & 2,59 & 2,55 & 6,88 & 0,04 \\
\hline Consumo de met+cis $(\mathrm{g} / \mathrm{dia})^{1}$ & 11,8 & 12,5 & 13,4 & 14,4 & 7,07 & 0,26 \\
\hline
\end{tabular}

${ }^{1}$ Efeito linear $(P<0,01)$. 
Tabela 3 - Características de carcaça de suínos machos castrados em terminação alimentados com rações suplementadas com ractopamina e diversas relações met+cis:lis

\begin{tabular}{|c|c|c|c|c|c|c|}
\hline \multirow[t]{2}{*}{ Variável } & \multicolumn{4}{|c|}{$\begin{array}{l}\text { Relação metionina + cistina digestível: } \\
\text { lisina digestível com ractopamina }\end{array}$} & \multirow[t]{2}{*}{$\mathrm{CV}(\%)$} & \multirow[t]{2}{*}{ EPM } \\
\hline & 0,54 & 0,58 & 0,62 & 0,66 & & \\
\hline Espessura de toucinho $(\mathrm{mm})$ & 12,68 & 14,00 & 12,63 & 14,58 & 11,78 & 0,31 \\
\hline Quantidade de carne magra (kg) & 46,83 & 46,22 & 46,85 & 45,91 & 3,68 & 0,31 \\
\hline Peso da carcaça $(\mathrm{kg})$ & 78,47 & 78,92 & 78,58 & 78,96 & 2,26 & 0,40 \\
\hline Porcentagem de carne magra $(\%)$ & 59,60 & 58,42 & 59,60 & 58,35 & 2,10 & 0,24 \\
\hline Índice de bonificação & 105,61 & 103,69 & 105,63 & 103,19 & 2,35 & 0,46 \\
\hline
\end{tabular}

(1998) de que a exigência de relação metionina + cistina digestível para suínos dos 72 aos 104 kg não é maior que $50 \%$ da exigência de lisina digestível da ração.

A menor relação 0,54 met+cis:lis foi suficiente para atender às exigências para maior desempenho e melhores características de carcaça, o que pode estar relacionado ao fato de que as exigências dos aminoácidos sulfurosos são controladas pela exigência de mantença, e não pela deposição de proteína, portanto, as exigências dos aminoácidos sulfurosos não aumentam proporcionalmente às exigências de lisina com o aumento da deposição de proteína (Mavromichalis \& Cera, 2001).

O rendimento de carcaça dos animais não foi influenciado $(\mathrm{P}>0,10)$ pelas relações met+cis:lis. Resultados diferentes foram reportados por Knowles et al. (1998), que verificaram efeito cúbico no rendimento de carcaça de suínos com o aumento da relação met+cis:lis na ração.

$\mathrm{O}$ índice de bonificação não foi influenciado $(\mathrm{P}>0,10)$ pelas relações met+cis:lis. Esse índice é calculado pelo frigorífico e raramente é abordado em estudos de avaliação das relações met+cis:lis.

As relações met+cis:lis influenciaram de forma quadrática $(\mathrm{P}<0,01)$ a concentração de colesterol no lombo (Figura 1). O menor teor de colesterol total foi verificado nos suínos alimentados com dietas contendo nível de met+cis correspondente à relação de $0,66 \mathrm{com}$ a lisina. As relações met+cis:lis influenciaram $(\mathrm{P}<0,03)$ o teor de colesterol total

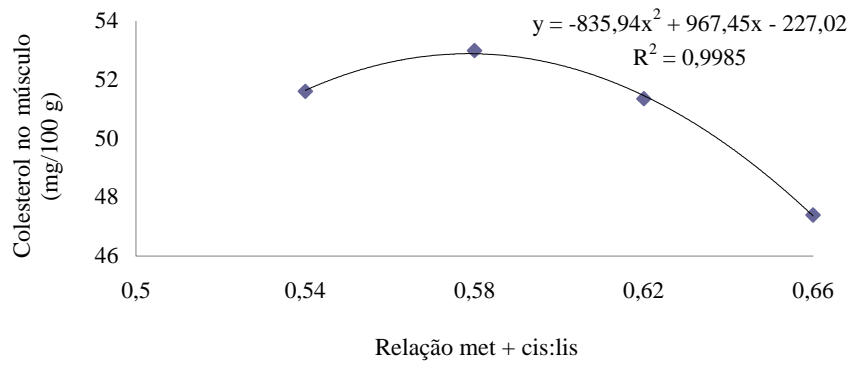

Figura 1 - Teor de colesterol total do músculo Longissimus dorsi de suínos sob suplementação com ractopamina e diversas relações metionina + cistina digestível/lisina digestível.

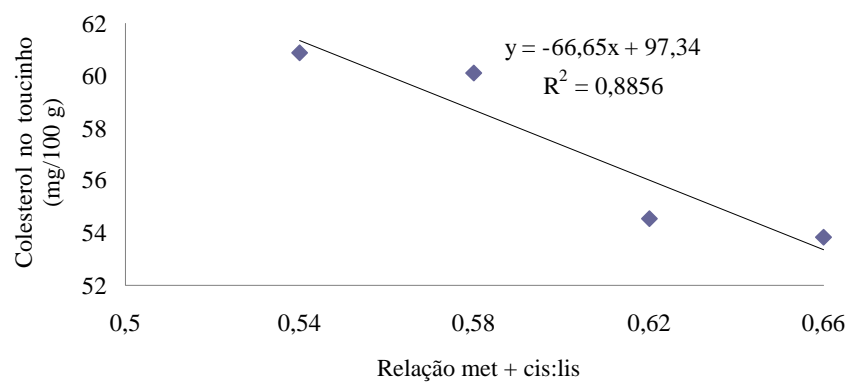

Figura 2 - Teor de colesterol total do toucinho de suínos sob suplementação com ractopamina e diversas relações metionina + cistina digestível/lisina digestível.

Tabela 4 - Resultados de colesterol total (mg/100 g) no lombo e toucinho de suínos machos castrados em terminação alimentados com rações suplementadas com ractopamina e diversas relações met+cis:lis

\begin{tabular}{lcccccc}
\hline Variável & \multicolumn{3}{c}{$\begin{array}{c}\text { Relação metionina + cistina digestível: } \\
\text { lisina digestível com ractopamina }\end{array}$} & CV (\%) & EPM \\
\cline { 2 - 6 } & 0,54 & 0,58 & 0,62 & 0,66 & 5,40 & 0,58 \\
Lombo $^{1}$ & 51,61 & 53,00 & 51,36 & 47,40 & 5,84 & 1,00 \\
Toucinho $^{2}$ & 60,88 & 60,11 & 54,57 & 53,84 & 8,89 \\
\hline
\end{tabular}

1 Efeito quadrático $(P<0,01)$.

2 Efeito linear $(P<0,03)$. 
no toucinho (Figura 2), que reduziu de forma linear e foi menor na relação 0,66 met+cis:lis. Apesar dessa redução significativa do nível de colesterol total, tanto no lombo quanto no toucinho, com o aumento da relação met+cis:lis na ração, não foi possível identificar as causas desta resposta.

\section{Conclusões}

Em suínos machos castrados de alto potencial genético sob suplementação com ractopamina na fase de terminação, a melhor relação metionina + cistina digestível:lisina digestível para melhor desempenho e melhores características de carcaça é de 0,54, que corresponde a $12 \mathrm{~g}$ de metionina + cistina digestível por dia. Para menor nível de colesterol no lombo e no toucinho, no entanto, a melhor relação é de 0,66 .

\section{Agradecimento}

À Elanco Saúde Animal, pelo financiamento do trabalho. À Coordenação de Aperfeiçoamento de Pessoal de Nível Superior (CAPES), pela concessão da bolsa de mestrado. À Empresa de Pesquisa Agropecuária de Minas Gerais (EPAMIG), pelo local de realização do experimento. Ao Frigorífico Industrial Vale do Piranga (FRIVAP), pela liberação do acompanhamento dos abates. Aos estudantes de graduação e pós-graduação, pela auxílio na condução do experimento.

\section{Literatura Citada}

APPLE, J.K.; MAXWELL, C.V.; BROWN, D.C. et al. Effects of dietary lysine and energy density on performance and carcass characteristics of finishing pigs fed ractopamine. Journal of Animal Science, v.82, p.3277-3287, 2004.

ARMSTRONG, T.A.; IVERS, D.J.; WAGNER, J.R. et al. The effect of dietary ractopamine concentration and duration of feeding on growth performance, carcass characteristics, and meat quality of finishing pigs. Journal of Animal Science, v.82, p.3245-3253, 2004.

DEAN, D.W. Amino acid requirements and low crude protein, amino acid supplemented diets for swine and poultry. Louisiana: Faculty of the Louisiana State University and Agricultural and Mechanical College, 2005. 120p. Thesis (Doctor of Philosophy), 2005.
KIEFER, C.; FERREIRA, A.S.; OLIVEIRA, R.F.M. et al. Exigência de metionina mais cistina digestíveis para suínos machos castrados mantidos em ambiente de alta temperatura dos 30 aos $60 \mathrm{~kg}$. Revista Brasileira de Zootecnia, v.34, n.1, p.104$111,2005$.

KNOWLES, T.A.; SOUTHERN, L.L.; BIDNER, T.D. Ratio of total sulphur amino acids to lysine for finishing pigs. Journal of Animal Science, v.76, p.1081-1090, 1998.

LOUGHMILLER, J.A.; GOODBAND, R.D.; TOKACH, M.D. et al. Evaluation of the total sulphur amino acid requirement of finishing pigs. Swine Day Report, p.130-132, 1996a.

LOUGHMILLER, J.A.; TOKACH, M.D.; GOODBAND, R.D. et al. Dietary total sulphur amino acid requirement for optimal growth performance and carcass characteristics in finishing gilts. Swine Day Report, p.133-135, 1996 b.

LOUGMILLER, J.A.; NELSEN, J.L.; GOODBAND, R.D. Influence of dietary total sulphur amino acids and methionine on growth performance and carcass characteristics of finishing gilts. Journal of Animal Science, v.76, p.2129-2137, 1998.

MANNO, M.C.; OLIVEIRA, R.F.M.; LOPES, J.L. et. al. Efeitos da temperatura ambiente sobre o desempenho de suínos dos 30 aos 60 kg. Revista Brasileira de Zootecnia, v.35, n.2, p.471477, 2006.

MARCHANT-FORDE, J.N.M.; LAY JR., D.C.; PAJOR, E.A. et al. The effects of ractopamine on the behaviour and physiology of finishing pigs. Journal of Animal Science, v.81, p.416422, 2003.

MAVROMICHALIS, I.D.; CERA, K.R. Update on ideal amino acid profile for finishing pigs. Feedstuffs, v.73, n.26, p.11-13, 2001.

NATIONAL PORK PRODUCERS COUNCIL - NPPC. Procedures to evaluate market hogs. 3.ed. Des Moines: 1991. 16p.

NOGUEIRA, G.C.; BRAGAGNOLO, N. Otimização da extração de colesterol em carne e quantificação por CLAE. In: CONGRESSO BRASILEIRO DE CIÊNCIA E TECNOLOGIA DE ALIMENTOS, 18., 2002, Porto Alegre. Anais... Porto Alegre: 2002. v.1. p.328-332.

ROSTAGNO, H.S.; ALBINO, L.F.T.; DONZELE, J.L. et al. Tabelas brasileiras para aves e suínos (Composição de alimentos e exigências nutricionais). Viçosa, MG: Universidade Federal de Viçosa, 2005. 186p.

SALDANHA, T.; MAZALI, M.R.; BRAGAGNOLO, N. Avaliação comparativa entre dois métodos para a determinação de colesterol em carne e leite. Ciência e Tecnologia de Alimentos, v.24, n.1, p.109-113, 2004.

SANTOS, F.A.; DONZELE, J.L.; OLIVEIRA, R.F.M. et al. Exigência de metionina + cistina digestíveis em suínos machos castrados de alto potencial genético na fase dos 60 aos $95 \mathrm{~kg}$. Revista Brasileira de Zootecnia, v.36, n.6 p.2047-2053, 2007 (supl.).

SCHINCKEL, A.P.; RICHERT, B.T.; KENDALL, D.C. [2000] Modeling the response to paylean and dietary lysine requirements. Disponível em: <http://www.ansc.purdue.edu/ swine/swineday/sday00/14.pdf> Acesso em: 19/6/08.

TAVAREZ, S.L.S.; DONZELE, J.L.; OLIVEIRA, R.F.M. et al. Influência da temperatura ambiente sobre o desempenho e os parâmetros fisiológicos de suínos machos castrados dos 30 aos 60 kg. Revista Brasileira de Zootecnia, v.29, p.199-205, 2000.

UNIVERSIDADE FEDERAL DE VIÇOSA - UFV. Sistema para análises estatísticas e genéticas - SAEG - Viçosa, MG: UFV. Versão 9.0. 2004. (CD-ROM). 